\title{
COMMENTARY
}

\section{Resuscitation of the trauma patient: tell me a trigger for early haemostatic resuscitation please!}

\author{
Matthew J Reed', Nazir Lone ${ }^{2,3}$ and Timothy S Walsh*3 \\ See related research by Stanworth et al., http://ccforum.com/content/14/6/R239
}

\begin{abstract}
The management of trauma-related coagulopathy and haemorrhage is changing from a reactive strategy to a proactive early intervention with blood products and haemostatic agents. Although major haemorrhage and massive transfusion are associated with higher mortality, the pattern of this association with modern trauma care is poorly described. In addition, early predictors of massive transfusion, which might trigger a proactive haemostatic resuscitation strategy, are not currently available. We review recent literature relating to predictors of massive transfusions and the relationship between transfusion and mortality.
\end{abstract}

Stanworth and colleagues have explored the relation between blood loss and mortality in trauma patients in a study stimulated by the changing approach to early trauma management [1]. The traditional approach advocates packed red blood cell (PRBC) transfusions and early coagulation testing in the hospital laboratory using assays such as the prothrombin time ratio, the activated partial thromboplastin time ratio, and platelet concentration. Transfusion of fresh frozen plasma, platelets, and sometimes cryoprecipitate was based on results that may be delayed for 60 minutes following sampling. Current guidelines recommend transfusion when prothrombin time ratio or activated partial thromboplastin time ratio $>1.5$, platelet count $<50 \times 10^{9} / \mathrm{l}$, or fibrinogen level $<1.5$ to $2.0 \mathrm{~g} / \mathrm{l}[2]$, or after a certain proportion of the circulating volume is lost. This approach is inherently reactive rather than proactive and is at risk of closing the door after the horse has bolted. Our increasing understanding that shock and hypoperfusion can initiate inflammation, which is

\footnotetext{
*Correspondence: twalsh@staffmail.ed.ac.uk

${ }^{3}$ Department of Critical Care, Clinical Sciences and Community Health, Edinburgh University and Royal Infirmary of Edinburgh, Little France Crescent, Edinburgh, EH16 4SA, UK

Full list of author information is available at the end of the article
}

closely linked to coagulation, creates biological plausibility that the traditional approach may not be best for injured patients.

Up to one-quarter of trauma patients have deranged coagulation on arrival in the emergency department [3], which is more severe with greater injury severity [3], acidosis and shock [4], and is associated with higher PRBC use and mortality [5]. This has led to the new concept of haemostatic resuscitation, which advocates point-of-care coagulation testing, higher ratios of fresh frozen plasma and platelets to PRBC, fresh whole blood where available, minimal crystalloid, and early consideration of cryoprecipitate, fibrinogen, activated recombinant factor VII and tranexamic acid [5-10]. Evidence from cohort studies suggests these interventions are associated with increased survival [7-10]. War in Iraq and Afghanistan has accelerated this area of research, and further high-quality evidence for military and civilian settings is highly desirable.

Because haemostatic resuscitation aims to hit the problem hard and early, the technique raises several challenges - especially the logistics of providing blood products quickly and safely. Perhaps most challenging is quickly recognising patients in whom early haemostatic resuscitation is indicated. Trauma patients have a wide range of injury severity, meaning fluid requirements range from nothing to massive transfusion. Unnecessary transfusion will drain systems of blood products in limited supply, and will increase the risk of transfusion complications.

Stanworth and colleagues have addressed this issue by analysing pooled data from trauma registries in five countries in Europe and North America [1]. They asked two questions: first, is there a threshold effect in PRBC use on hospital mortality? Second, can clinical and laboratory parameters available soon after arrival in the emergency department predict who will go on to require massive PRBC transfusion? If a threshold value was found, this might be a useful way of triaging patients, whereas predictive early parameters might be used as a diagnostic test to trigger major haemorrhage protocols and the use of haemostatic resuscitation. 
Using complex statistical modelling methods, the authors found a clear relationship between the number of PRBCs transfused in the first 24 hours and death rates, but no threshold effect. This observation suggests we should not use arbitrary thresholds of blood loss or blood product use in conceptualising the risk of death, but should acknowledge that all increments represent progressive increased risk. The external validity of the findings needs to acknowledge the fact that the centres involved were well established with high levels of expertise in trauma management, and the relationship might be different in other healthcare organisations. The many factors that influence trauma outcomes also mean that effect modifiers could alter the relationship between PRBC transfusion and mortality. The authors provide compelling evidence that with modern trauma care there is no obvious ceiling effect, however, and they emphasise the biological plausibility of using ongoing PRBC requirement as an index of mortality risk.

Despite the lack of threshold effect, the authors developed a model to predict massive PRBC transfusion using receipt of at least 10 PRBC units to define massive transfusion. Potential predictor variables were mathematically transformed to optimise the fitting of the model. Although this transformation improved the mathematics of the model, clinicians are left somewhat perplexed in interpreting the effect on transfusion risk of a unit change in, for example, the reciprocal of the natural log of prothrombin time squared! In the model, admission systolic blood pressure, base deficit, and prothrombin time had strongest association with receiving massive transfusion. These associated parameters are not new, but confirm what is already known. Including the prothrombin time in a model would limit the value of the score due to the delay in laboratory processing of these samples. When sensitivity in the model was set at $90 \%$, a clinically useful cut-off point, the specificity was only $50 \%$, correctly classifying only $58 \%$ of patients. This means that if this score was used to initiate a major haemorrhage protocol and/or haemostatic resuscitation with PRBCs, fresh frozen plasma, and platelets, this would lead to an inappropriate activation on $50 \%$ of occasions (based on the 10 PRBC unit cut-off point). On one hand this might be considered an inappropriate use of blood products, but if this method reduced mortality, complications or illness cost - especially given the relatively linear relationship between PRBC transfusion and death shown in the first model - it might be considered clinically effective and cost-effective. Highquality clinical trials of haemostatic resuscitation therapy may help us answer this question.

It would be interesting to compare the performance of this predictive model with other published trauma scores, such as the Trauma Associated Severe
Hemorrhage score [11] or the Assessment of Blood Consumption score [12], which only used parameters available within the first 15 to 20 minutes of arrival in the emergency department. The Trauma Associated Severe Hemorrhage score correctly classified $89 \%$ of cases requiring massive transfusion, and the Assessment of Blood Consumption score 85\%. These scores were developed in smaller cohorts, however, and whether this performance can be replicated in international cohorts remains to be seen.

Where does this leave us? The recent CRASH-2 trial of tranexamic acid in trauma has shown that simple cheap interventions which modify coagulation can improve survival in trauma patients [10]. Clarifying the further impact of more complex and expensive strategies is therefore clearly warranted, because any reduction in coagulopathy and/or PRBC transfusion in this setting is likely to modify outcome. Despite the large databases and complex statistical modelling, Stanworth and colleagues have not provided any new predictors for when to intervene. We therefore need to continue to search for better predictors that could be available within minutes of presentation, perhaps based on thromboelastography or individual factor levels. Until then, as is usually the case in critical care, emphasis should be placed on early assessment and continual reassessment by experienced clinicians working in an organisation capable of delivering therapies quickly and effectively.

\section{Abbreviations}

PRBC, packed red blood cell.

\section{Author details}

'Emergency Department, Royal Infirmary of Edinburgh, 51 Little France Crescent, Edinburgh EH16 4SA, UK. ${ }^{2}$ Department of Public Health Sciences, Edinburgh University, Teviot Place, Edinburgh, EH8 9AG, UK. ${ }^{3}$ Department of Critical Care, Clinical Sciences and Community Health, Edinburgh University and Royal Infirmary of Edinburgh, Little France Crescent, Edinburgh, EH16 4SA, UK.

\section{Competing interests}

The authors declare that they have no competing interests.

Published: 1 March 2011

\section{References}

1. Stanworth SJ, Morris TP, Gaardner C, Goslings JC, Maegele M, Cohen MJ, Konig TC, Davenport RA, Pittet J-F, Johansson PI, Allard S, Johnson T, Brohi K: Trauma related massive transfusion: can we predict it? An analysis or five large trauma datasets. Crit Care 2010, 14:R239.

2. Rossaint R, Bouillon B, Cerny V, Coats TJ, Duranteau J, Fernández-Mondéjar E, Hunt BJ, Komadina R, Nardi G, Neugebauer E, Ozier Y, Riddez L, Schultz A, Stahel PF, Vincent J-L, Spahn DR: Management of bleeding following major trauma: an updated European guideline. Crit Care 2010, 14:R52.

3. Brohi K, Singh J, Heron M, Coats T: Acute traumatic coagulopathy. J Trauma 2003, 54:1127-1130.

4. Brohi K, Cohen MJ, Ganter MT, Matthay MA, Mackersie RC, Pittet JF: Acute traumatic coagulopathy: initiated by hypoperfusion: modulated through the protein C pathway? Ann Surg 2007, 245:812-818.

5. Gonzalez EQ: Fresh frozen plasma should be given earlier to patients requiring massive transfusion. J Trauma 2007, 62:112-119.

6. Carroll RC, Craft RM, Langdon RJ: Early evaluation of acute traumatic 
coagulopathy by thrombelastography. Trans/ Res CCM 2009, 154:34-39.

7. Borgman MA, Spinella PC, Perkins JG: The ratio of blood products transfusion affects mortality in patients receiving massive transfusions at a combat support hospital. J Trauma 2007, 63:805-813.

8. Holcomb JB, Wade CE, Michalek JE, Chisholm GB, Zarzabal LA, Schreiber MA, Gonzalez EA, Pomper GJ, Perkins JG, Spinella PC, Williams KL, Park MS: Increased plasma and platelet to red blood cell ratios improves outcome in 466 massively transfused civilian trauma patients. Ann Surg 2008, 248:447-458.

9. Shaz BH, Young A, Harris R, Nicholas J, Hillyer CD, Dente C: Increased number of plasma products in relationship to red blood cell products transfused improves mortality in trauma patients [abstract]. Transfusion 2008, 48(Suppl 2):25a-26a.

10. CRASH-2 trial collaborators; Shakur H, Roberts I, Bautista R, Caballero J, Coats T, Dewan Y, El-Sayed H, Gogichaishvili T, Gupta S, Herrera J, Hunt B, Iribhogbe P, Izurieta M, Khamis H, Komolafe E, Marrero MA, Mejía-Mantilla J, Miranda J, Morales C, Olaomi O, Olldashi F, Perel P, Peto R, Ramana PV, Ravi RR,

Yutthakasemsunt $\mathrm{S}$ : Effects of tranexamic acid on death, vascular occlusive events, and blood transfusion in trauma patients with significant haemorrhage (CRASH-2): a randomised, placebo-controlled trial. Lancet 2010, 376:23-32

11. Yücel $N$, Lefering $R$, Maegele $M$, Vorweg M, Tjardes T, Ruchholtz $S$, Neugebauer EA, Wappler F, Bouillon B, Rixen D; Polytrauma Study Group o the German Trauma Society: Trauma Associated Severe Hemorrhage (TASH)-score: probability of mass transfusion as surrogate for life threatening hemorrhage after multiple trauma. J Trauma 2006, 60:1228-1236.

12. Nunez TC, Voskresensky IV, Dossett LA, Shinall R, Dutton WD, Cotton BA: Early prediction of massive transfusion in trauma: simple as $A B C$ (assessment of blood consumption)? J Trauma 2009, 66:346-352

doi:10.1186/cc10014

Cite this article as: Reed MJ, et al.: Resuscitation of the trauma patient: tell me a trigger for early haemostatic resuscitation please! Critical Care 2011, 15:126. 